\title{
EXPERIMENTAL AND NUMERICAL STUDY OF THE EFFECT OF MIXING CHAMBER LENGTH AND AREA RATIO ON THE PERFORMANCE OF A SUBSONIC AIR-AIR EJECTOR
}

\author{
Tarek A. Meakhail \\ Mechanical Power Engineering Department, High Institute of Energy, \\ South Valley University, Aswan, Egypt
}

(Received January 3, 2009; Accepted January 21, 2009)

\begin{abstract}
This paper presents the results of experimental investigation and Computational Fluid Dynamic (CFD) analysis of an air-air subsonic ejector. The CFD modeling is used to investigate the effect of mixing chamber length and area ratio (ratio of nozzle area to mixing chamber area) on the performance of the experimentally tested ejector. For short mixing chamber to diameter ratio $M C=1.76$ it is found that the separation region in the annular part occurs along the whole length of mixing chamber and extends to 60 percent of the diffuser length and the flow reattaches at an axial distance to diameter ratio $X / D=5$. Increasing the mixing chamber length to $M C=4.76,6.76,9.76$ and 14.76 , reduces the area of separation and the reattaching flow begins at an average value of axial distance $X / D=3.25$. Increasing the $M C$ to a value more than 6.76 has no meaning in the mixing process as it increases the friction losses in the mixing chamber.

Increasing the area ratio from $A R_{1}=0.057$ to $A R_{2}=0.171$, the massive recirculation zone in the mixing chamber is reduced by about 50 percent and the pressure ratio increased by 21 percent with increasing the efficiency by 22 percent.

Finally, the numerical performance curve agrees well with the experimental one.
\end{abstract}

KEYWORDS: Subsonic ejector, CFD, Mixing chamber length, Area ratio.

\section{INTRODUCTION}

Ejectors are simple, versatile devices which have been used in a wide range of industrial settings since the early part of the previous century. Typical applications include the pumping and mixing of fluid, the creation of a vacuum, thrust augmentation for advanced aircraft, utilization in combustion and boundary layer control systems, refrigeration systems, etc. Because they have no moving parts, ejectors are economical, reliable, and have low maintenance requirements. They are particularly attractive for applications requiring intermittent use in remote locations where external power sources are unavailable and in situation where corrosive fluids must be handled.

The main components of an ejector are the primary jet nozzle and mixing chamber (also called the shroud). A diffuser and a secondary inlet nozzle are generally added to improve static recovery and reduce inlet losses, respectively. 
Several previous investigators have studied the use of ejectors in various applications. Dotterweith and Moony [1] considered the pumping of gas in a low pressure line by means of an ejector used in conjunction with a high pressure gas line. A simple empirical analysis based on experimental measurements was presented. Clanton [2] used a very similar method to design an ejector system which improved the production of a marginal gas well. Gas from a nearby production well was used as the source of primary flow. Da-Wen Sun [3] studied the performance of variable geometry ejectors and their applications in ejector refrigeration systems. Recent studies have shown that variable geometry ejectors play an important role in achieving optimal performance. The effect of ejector geometries on the performance was analyzed. Technical data including flow rates, entrainment ratio and ejector geometry were provided for a $5 \mathrm{~kW}$ steam-jet refrigerator. The given data may serve as guides in designing ejector cycle refrigerators with other cooling capacities.

The effects of different operating conditions such as nozzle velocity, pressure drop, and ejector geometry parameters on the performance of ejectors have been experimentally investigated by several researchers (Jackson, [4]; Davies et al., [5]; Bhat et al., [6]; Biswas, [7]; Bhutada and Pangarkar, [8]; Bando et al., [9] ; Havelka et al., [10]).

The problem to be considered in this paper is to study the effect of mixing chamber length and area ratio on the performance of the ejector experimentally and numerically.

Discussion of experimental results obtained here is difficult without obtaining detailed information about the separation regimes. There is a lack of understanding the details of the flow inside different parts of the ejector at different conditions. There is thus a need to develop a better understanding of flow inside the ejector system. Computational Fluid Dynamics (CFD) modeling approach is therefore utilized in this study to understand the details of the flow qualitatively and quantitatively inside the ejector that experimentally tested.

\section{TEST RIG}

The experimental test rig shown in Fig. 1 is used in the present study and the test section is shown in Fig. 2.

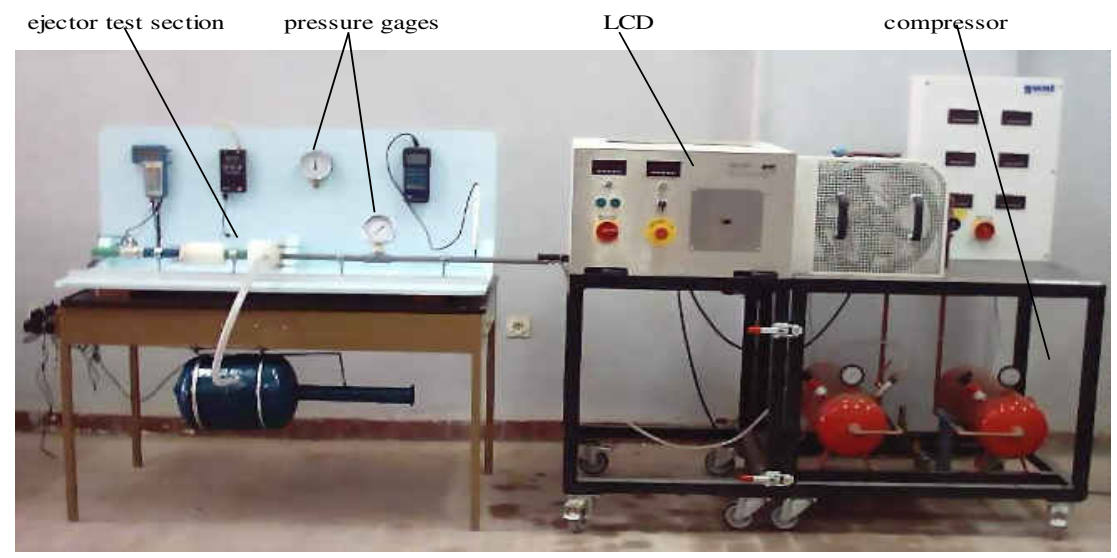

Fig. 1 Experimental apparatus 


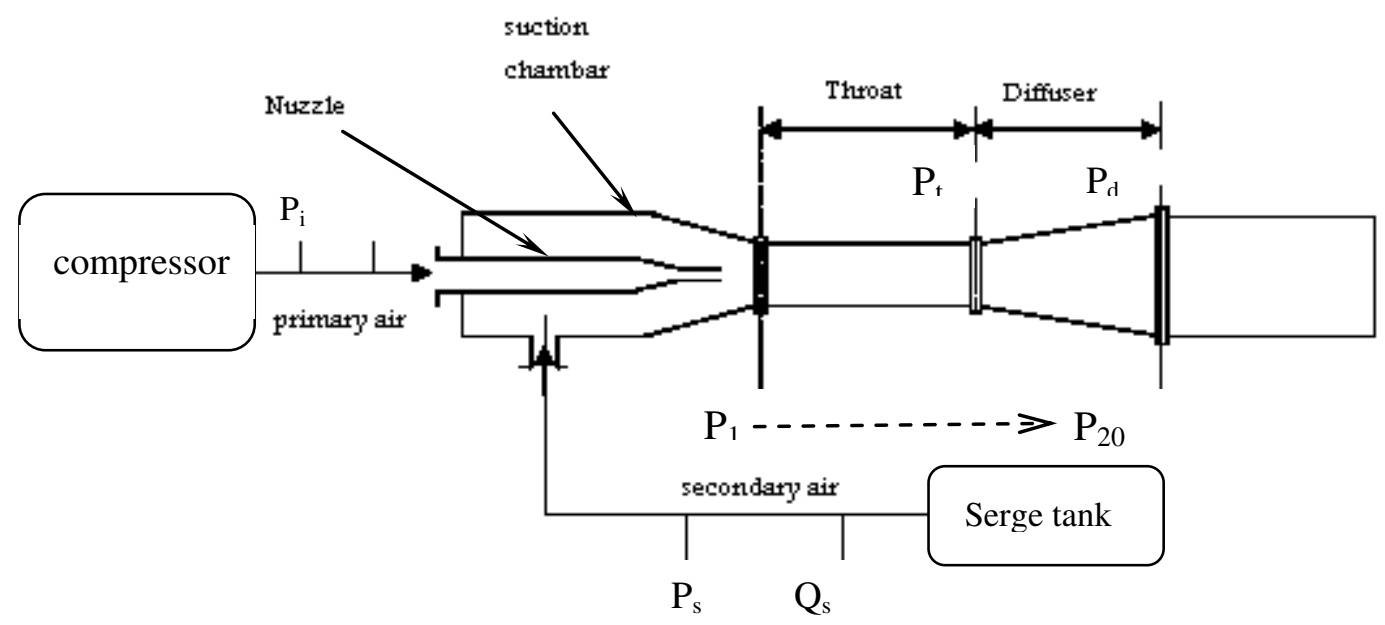

Fig. 2 The test section

Five mixing chambers are tested as well as two area ratios (nozzle to mixing chamber area ratio). The inlet diameter of the nozzle is $7 \mathrm{~mm}$ and its exit diameter is 5 $\mathrm{mm}$. The diameter of the mixing chamber is $\mathrm{D}_{\mathrm{mc}}=21 \mathrm{~mm}$ and their lengths are $\mathrm{L}_{\mathrm{mc}}=37$, $100,142,205,310 \mathrm{~mm}$, respectively. The mixing chamber length to diameter ratio $\mathrm{MC}=1.76,4.76,6.76,9.76$, and 14.76 , respectively. The nozzle to mixing chamber area ratio is $\mathrm{AR} 1=0.057$, which is low. The higher area ratio is also tested $\mathrm{AR}_{2}=0.171$ which is three times the previous one $\left(D_{m c}=12 \mathrm{~mm}\right.$ with the same nozzle $)$ and $M C=6$ times its diameter $\left(\mathrm{L}_{\mathrm{mc}}=72 \mathrm{~mm}\right)$. The half cone angle of the diffuser is $7 \mathrm{o}$ and its length is $110 \mathrm{~mm}$.

The measured variables are the suction flow rate Qs, the primary flow rate Qi, the discharge pressure; Pd, the suction pressure Ps and the driving pressure Pi. The ejector pressure ratio is calculated from

$$
\left(P_{r}=\frac{\left(P_{d}-P_{s}\right)}{\left(P_{i}-P_{d}\right)}\right)
$$

The mass flow ratio $(\phi)$ is the (secondary flow/primary flow), and the ejector efficiency can be calculated from the equation:

$$
\eta_{\text {ej }}=\frac{E_{\text {out }}}{E_{\text {in }}}=\frac{\rho_{s} Q_{s}\left(P_{d}-P_{s}\right)}{\rho_{i} Q_{i}\left(P_{i}-P_{d}\right)}=\phi P_{r}
$$

\section{CFD MODELING}

The commercially available CFD code, CFX-Tascflow [11] is employed for this study. The code solves the Reynolds averaged Navier-Stokes equations in primitive variable form. The effects of turbulence were modeled using the standard $\mathrm{K}-\varepsilon$ turbulence model. To make the simulation time economical, wall function is used to resolve the wall flows. Since the maximum Mach number is 0.47 the flow is treated as compressible flow. Hence, a steady-state 3-D compressible flow using turbulent model 
was employed for the solution of the problem. The governing equations implemented in the code are shown in the Appendix 2.

A high quality mesh is produced using a single block H-grid through different parts of the ejector. The minimum skew angle is less than 20 degree and the maximum aspect ratio is less than 100. Figure 3 shows the grid of the whole ejector. The total number of grid nodes is about 400,000 nodes. To ensure that the number of grid nodes used is sufficient to get convergent solution, an iteration of 'grid independent solution' is carried out. The total number of grid nodes is taken about 500,000. The results obtained in this case coincided with the results obtained with grid nodes of 400,000 nodes.

The boundary conditions were taken from the experimental work near the Best Efficiency Point. The no-slip boundary conditions are applied at all walls. Table 1 shows the all cases and their boundary conditions.

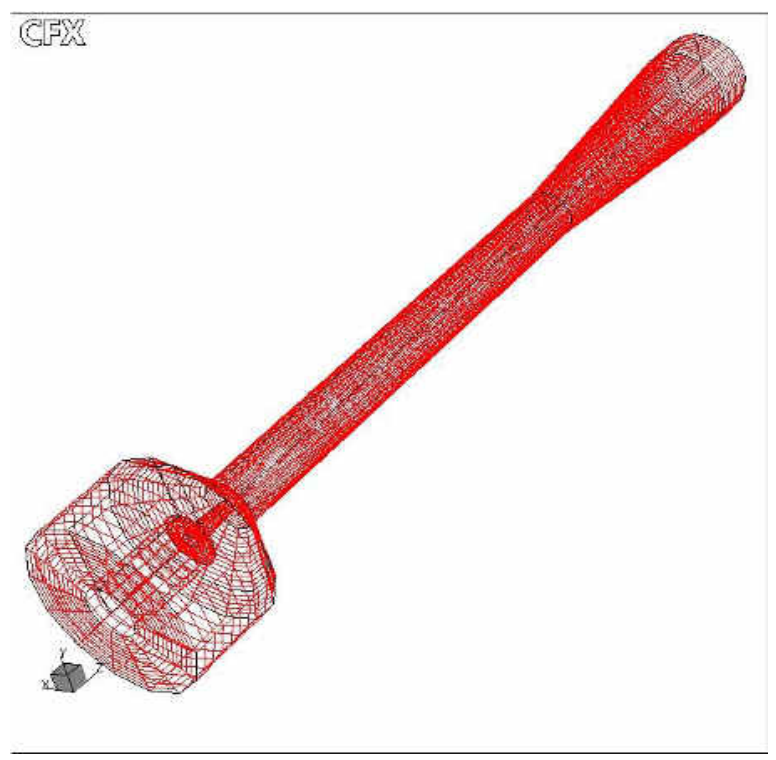

Fig. 3 The grid system

Table 1 Boundary conditions for all cases

\begin{tabular}{|l|c|c|l|l|}
\hline Case & MC & Pout $(\mathrm{pa})$ & $\mathrm{Mi}(\mathrm{Kg} / \mathrm{s})$ & $\mathrm{Ms}(\mathrm{Kg} / \mathrm{s})$ \\
\hline \multirow{4}{*}{$\mathrm{AR}_{1}=0.057$} & 1.76 & 103352 & 0.00373 & 0.001865 \\
\cline { 2 - 5 } & 4.76 & 103503 & 0.00373 & 0.001865 \\
\cline { 2 - 5 } & 6.76 & 103619 & 0.00373 & 0.001865 \\
\cline { 2 - 5 } & 9.76 & 103383 & 0.00373 & 0.001865 \\
\cline { 2 - 5 } & 14.76 & 103321 & 0.00373 & 0.001865 \\
\hline $\mathrm{AR}_{2}=0.171$ & 6 & 103950 & 0.00373 & 0.002 \\
\hline
\end{tabular}

\section{RESULTS AND DISCUSSION}

The main performance characteristics of the ejector are the pressure ratio $(\operatorname{Pr})$ and the overall efficiency ( $\eta$ ej) versus the mass flow ratio $(\phi)$ 


\subsection{Mixing chamber length}

Figure 4-a, $\mathrm{b}$ show the main characteristics for the ejector for $\mathrm{MC}=1.76,4.76,6.76$, 9.76, and 14.76 and area ratio $\mathrm{AR}_{1}=0.057$

From the figure, the lower efficiency and pressure ratio are for short mixing chamber $(\mathrm{MC}=1.76)$ and long mixing chamber $(\mathrm{MC}=9.76$ and 14.76$)$, the medium mixing chamber $(\mathrm{MC}=4.76$ and 6.76) gives better efficiency and pressure ratio and the $\mathrm{MC}=6.76$ gives the best results, $\eta \max =16.03 \%$ at $\phi \approx 0.5$.
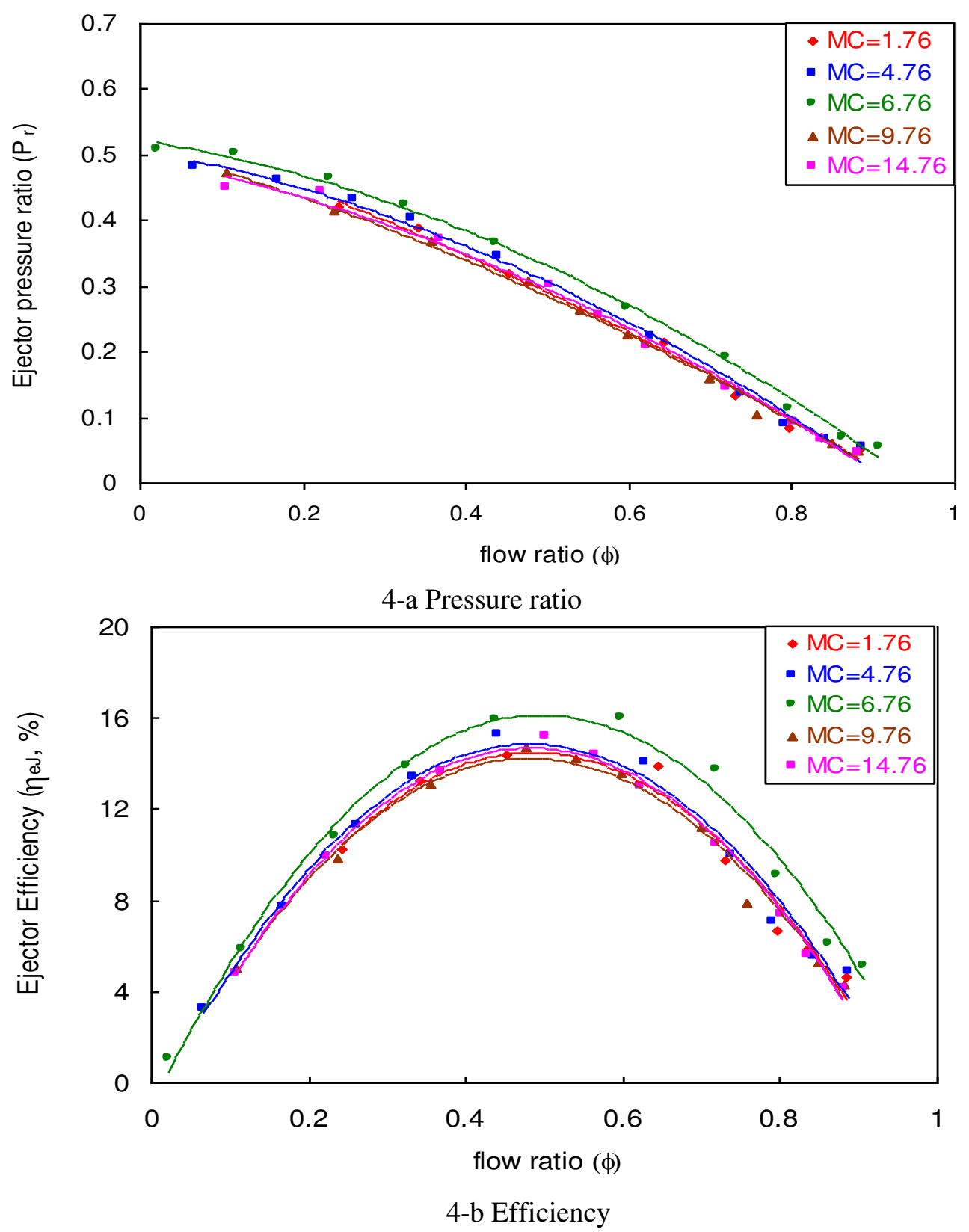

Fig. 4 Performance characteristics $\left(\mathrm{AR}_{1}=0.057\right)$ 
The detailed flow of the ejector may be determined either by detailed measurements which is not easily available or to investigate visually the flow pattern and the mixing process within the mixing chamber and diffuser using CFD modeling. The data that could be evaluated here include variation of the velocity vectors and its contours. The velocity vectors, in particular, are very useful when investigating the mixing process within the mixing chamber, as these show the flow directions and the relative velocity magnitudes.

Analyzing the flow using CFD, Fig 5-a,b,c,d and e shows the axial velocity vectors (W) at some selected sections and its contours in the mixing chamber and a part of the diffuser.

In Fig. 5-a, for short mixing chamber $(\mathrm{MC}=1.76)$, a highly separated flow regime is found in the whole mixing chamber and extends to $60 \%$ of the diffuser length. The reattaching flow begins at an axial distance ratio $\mathrm{X} / \mathrm{D}=5$. Increasing the mixing chamber length ratio to $\mathrm{MC}=4.76,6.76,9.76$ and 14.76 contracts the separated flow regimes and the reattaching flow begins at an average value of axial distance ratio $\mathrm{X} / \mathrm{D}=3.25$ as shown in Fig. 5-b,c,d,e and the flow enters the diffuser without any separation.

Comparing the short length of mixing chamber i.e, $\mathrm{MC}=1.67$, Fig. 5-a, with the higher lengths $(\mathrm{MC}=4.76,6.76,9.76$ and 14.76 Fig. 5-b, c, d, e), it should be pointed out here that the existence of the diffuser entrance in the separated flow regimes at the outlet of the mixing chamber causes more extension of the separation regimes to higher axial distance ratio i.e., at $\mathrm{X} / \mathrm{D}=5$. Also, increasing the $\mathrm{MC}$ to a value more than 6.76 has no meaning in the mixing process as it increases the friction losses in the mixing chamber.

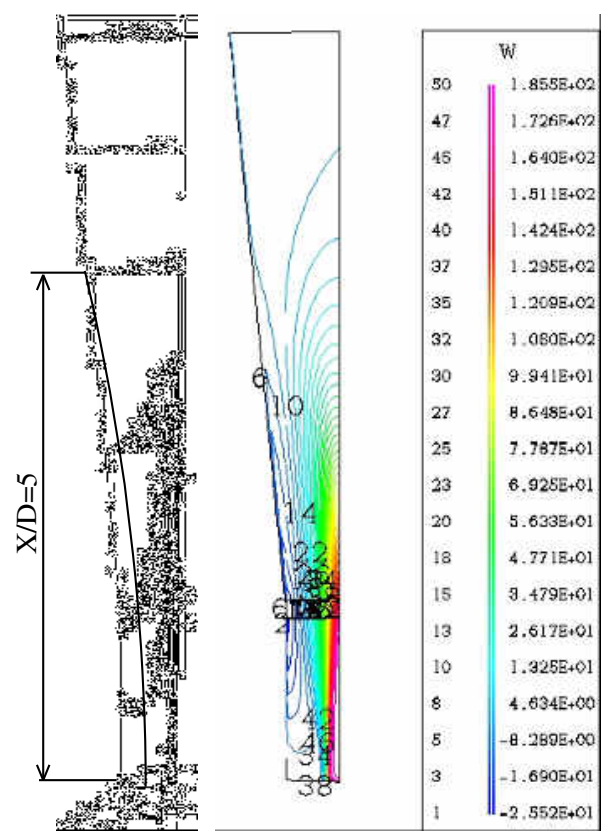

a- $\mathrm{MC}=1.76$

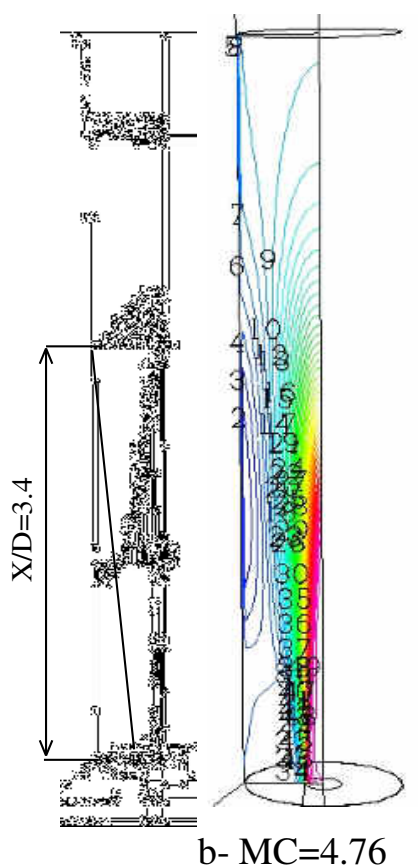

b- $\mathrm{MC}=4.76$

Fig. 5 Axial velocity vectors and its contours, $\mathrm{AR}_{1}=0.057$ 

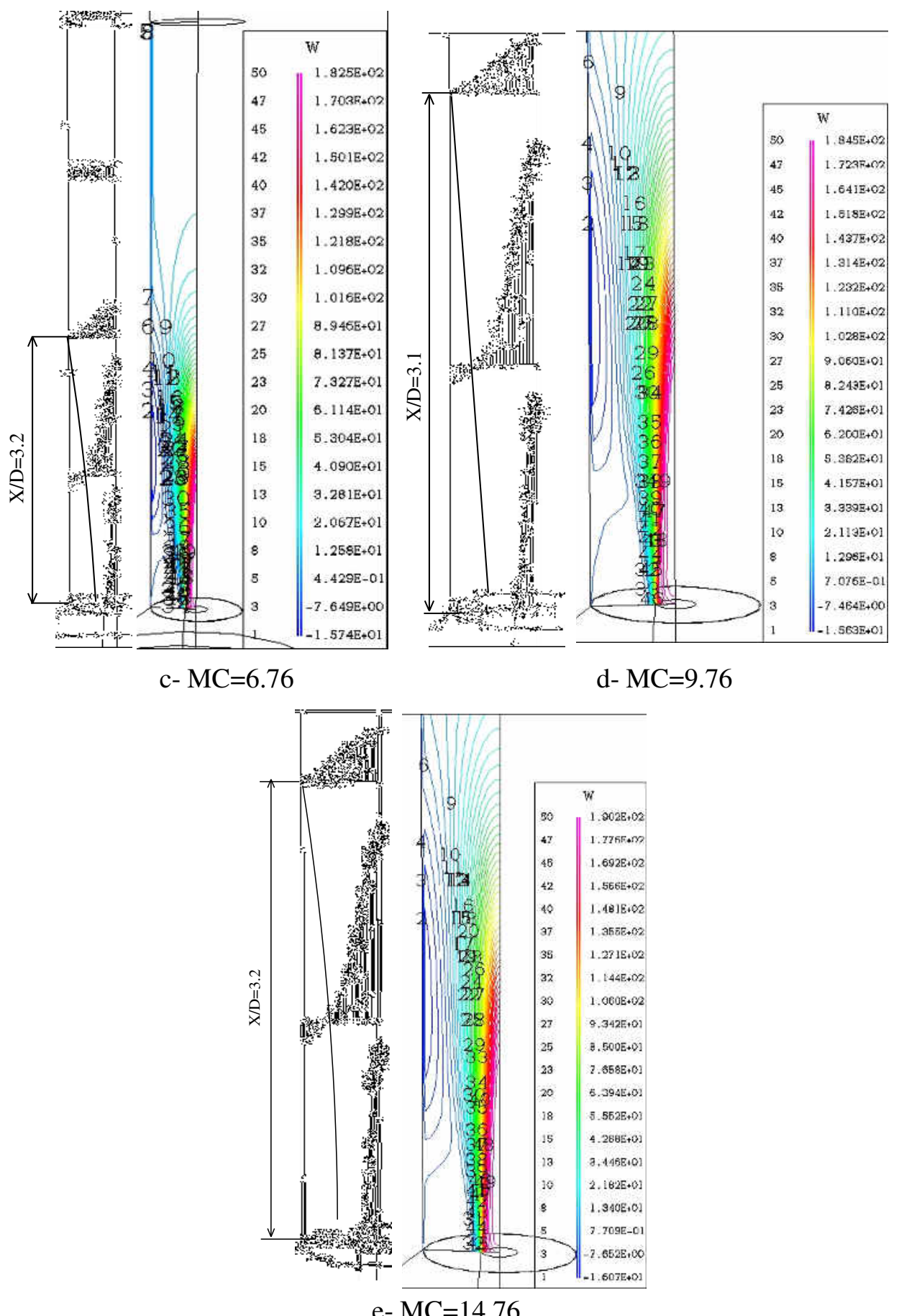

Fig. 5 Axial velocity vectors and its contours, $A_{1}=0.057$ (continued)

\subsection{Effect of area ratio}

For fixed nozzle area the mixing chamber diameter has been reduced to give an area ratio three times the original one i.e, $\mathrm{AR}_{2}=0.171$ with mixing chamber length to 
diameter ratio $\mathrm{MC}=6$. The performance curves are obtained and compared with that of lower area ratio $\mathrm{AR}_{1}=0.057$ at $\mathrm{MC}=6.76$ as shown in Fig. 6-a,b. From the figure, the maximum efficiency occurs at $\phi \approx 0.5$ and the corresponding pressure ratio increases from $\operatorname{Pr}=0.32$ to $\operatorname{Pr}=.39$ i.e., the increased percentage is 21 percent while the maximum efficiency $\phi \approx 0.5$ increases from $\eta=16.3$ to $\eta=20$ percent with an increasing percentage of 22 percent.

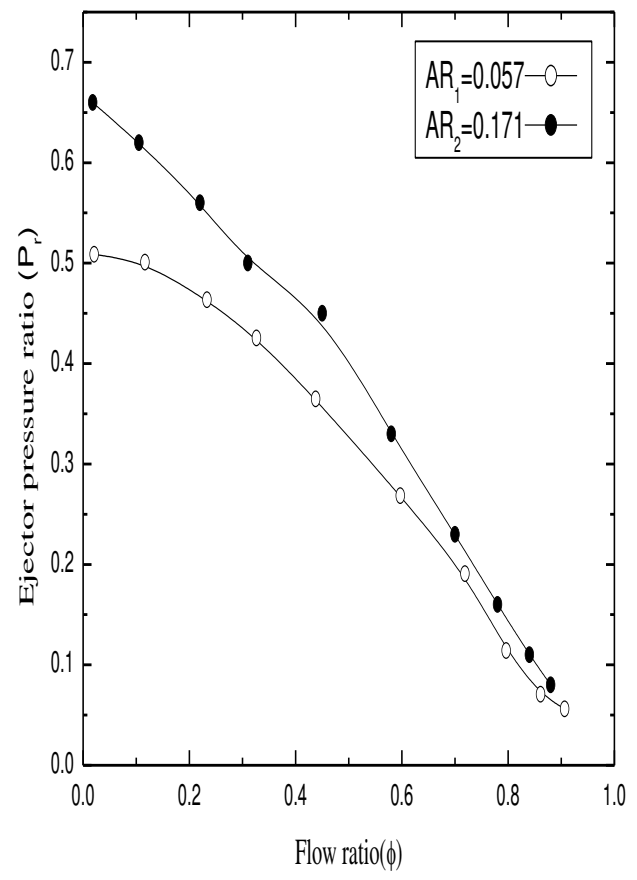

a- Pressure ratio

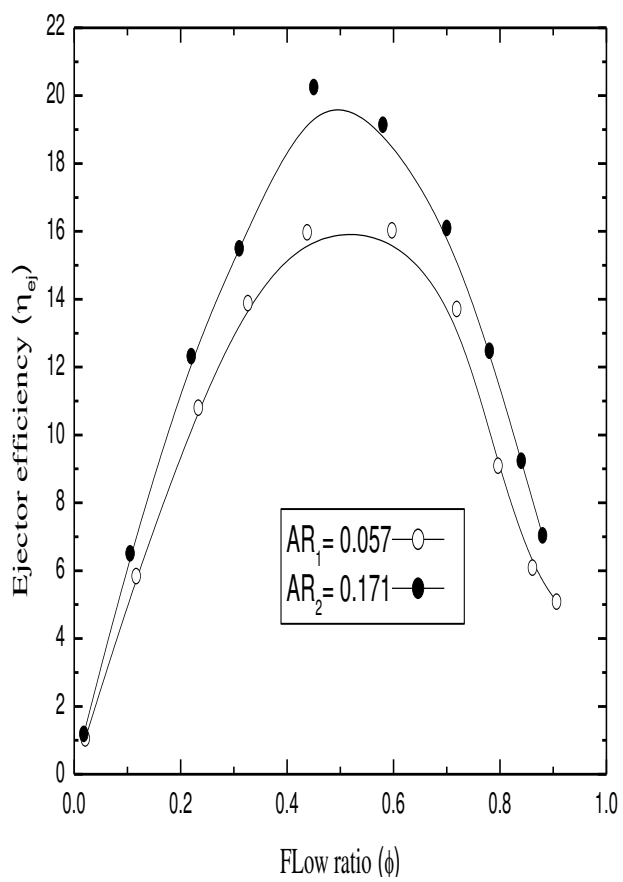

b- efficiency

Fig. 6 Performance characteristics

Analyzing the flow details in the mixing chamber region, it can be easily discuss the reason of why the pressure ratio and hence the efficiency increased in case of higher area ratio $\mathrm{AR}_{2}=0.171$. Figure $7-\mathrm{a}, \mathrm{b}$ shows the axial velocity vectors and its contours for both area ratios. From the figure, the recirculation zone in case of higher area ratio has been reduced strongly. The relative radial distance $(y / R)$ at which the maximum recirculation occurs has been reduced from 32 percent in case of $\mathrm{AR}_{1}=0.057$ to 16 percent in case of $\mathrm{AR}_{2}=0.171$. Quantifying the axial velocity component (W) in both cases, Fig. 8 shows the axial velocity ratio (W/Wmean) along the radius at which the maximum recirculation occurs at both cases. From the figure, the axial velocity in case of higher area ratio $\mathrm{AR}_{2}=0.171$ is higher than that of lower area ratio $\mathrm{AR}_{1}=0.057$, this means that in the case of $\mathrm{AR}_{2}=0.171$ much more flow can be entrained, moreover, the reverse flow zone in case of lower area ratio $\mathrm{AR}_{1}=0.057$ is higher than the case of higher area ratio that causes blockage of the flow. 

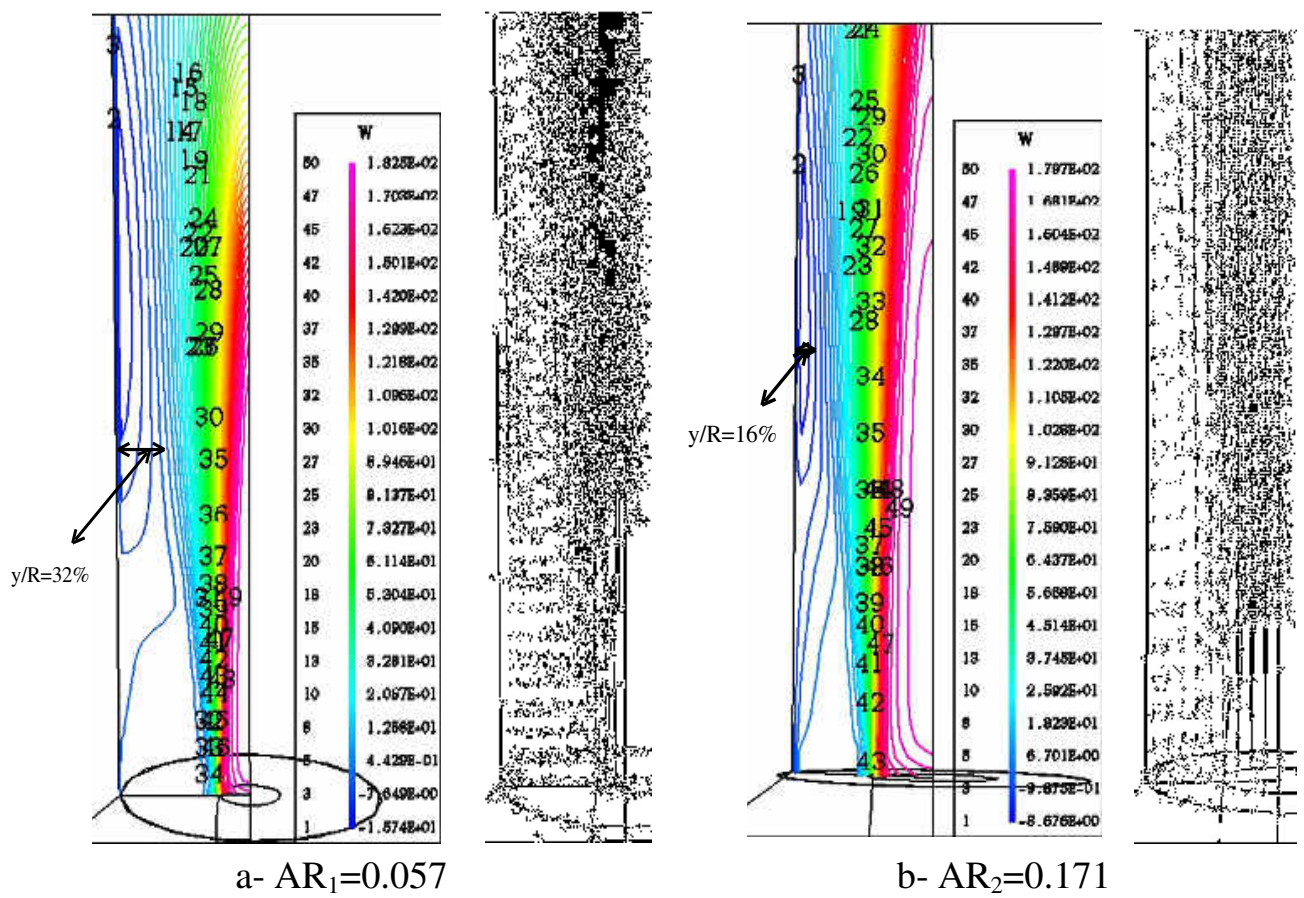

Fig. 7 Axial velocity vectors and its contours

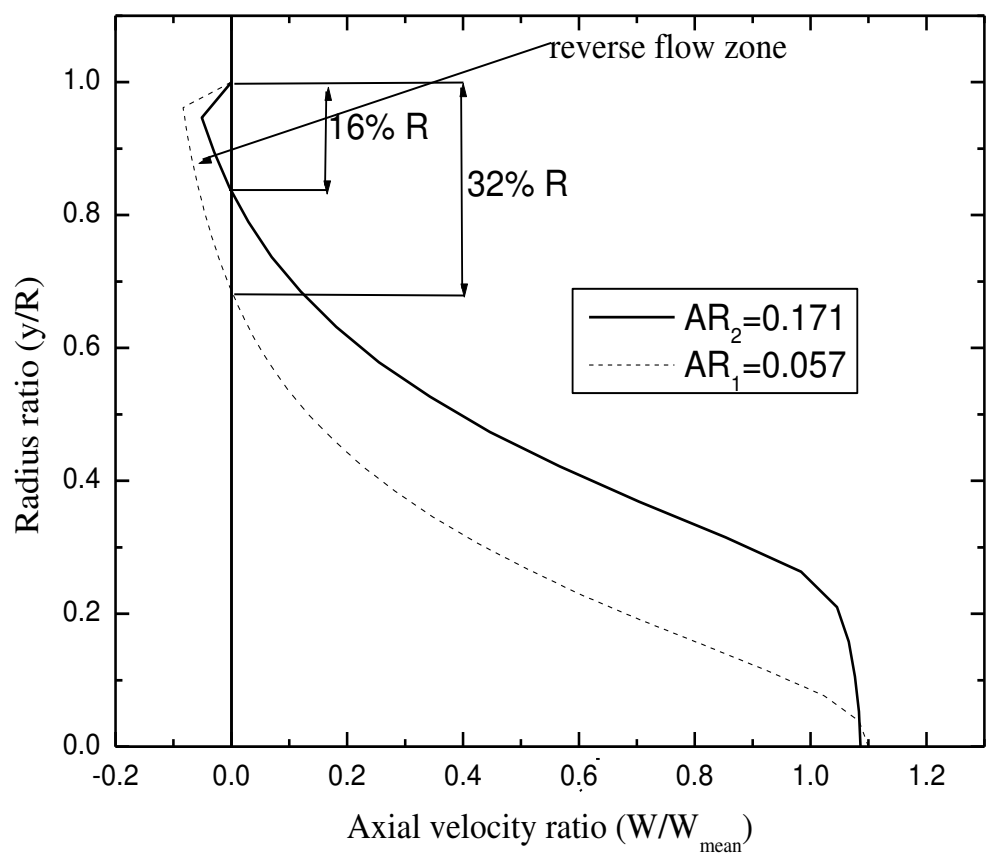

Fig. 8 Axial velocity ratio at maximum recirculation

To ensure that the flow is still subsonic along the mixing chamber, the Mach number contours are plotted in Fig. 9, as shown from the figure, and the maximum local Mach number could be reached is around 0.5. 


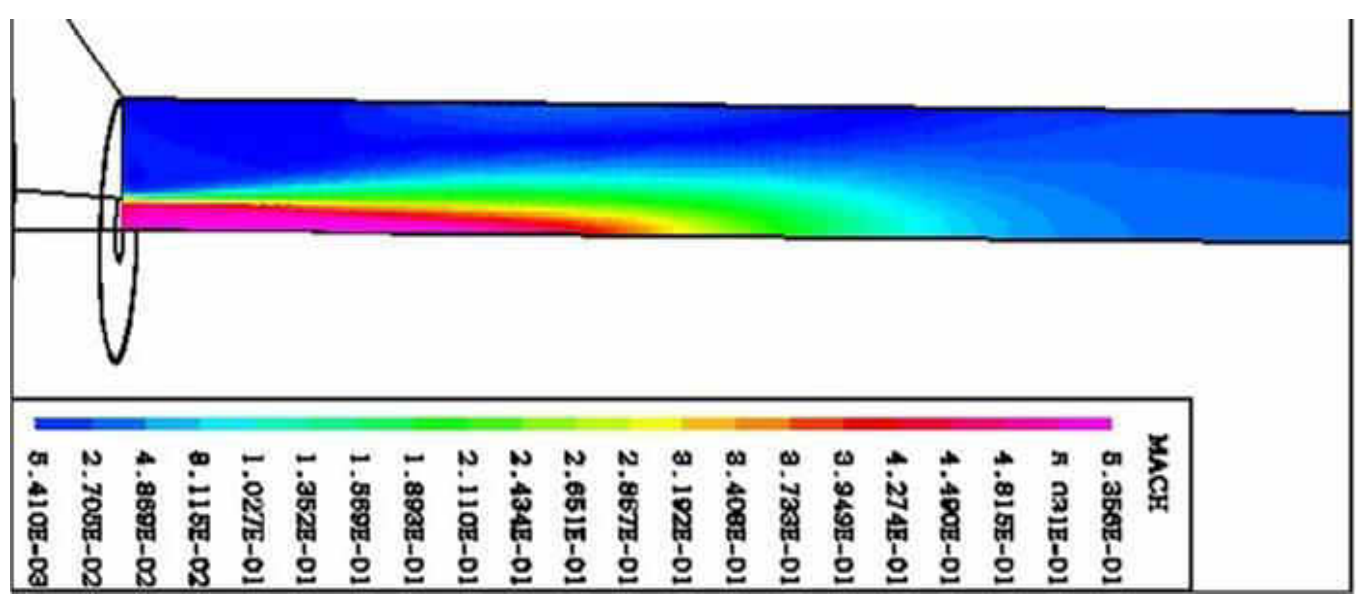

Fig. 9 Mach number contours

Finally, performance comparisons between the experimental and numerical results are obtained. Figure 10 shows the case of $\mathrm{MC}=6.76$ and $\mathrm{AR}_{1}=0.057$. As shown from the figure, the discrepancy between the two curves is less than $5 \%$.

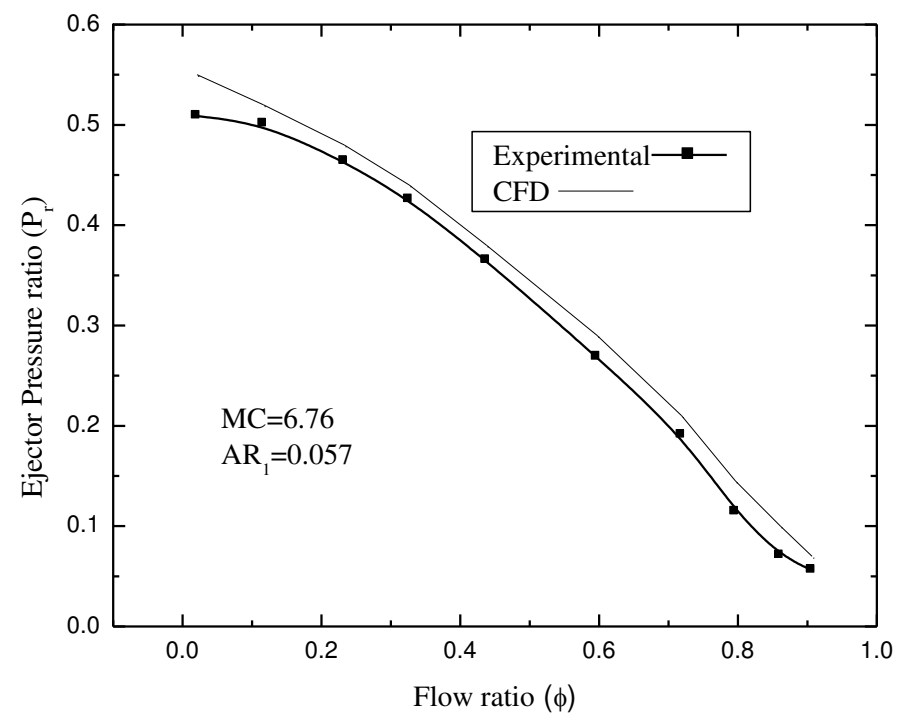

Fig. 10 Comparison between experimental and CFD

\section{CONCLUSIONS}

This paper presented results of Computational Fluid Dynamics (CFD) analysis and experimental investigations of an air-air subsonic ejector. CFD was found to be a very useful tool which can be employed to quantitatively and qualitatively analyze the separation regimes in mixing camber and diffuser. It can be concluded that:

1- For short mixing chamber, $\mathrm{MC}=1.76$, highly separated flow regime is found in the whole mixing chamber and extends to $60 \%$ of the diffuser length. The reattaching flow begins at an axial distance ratio $\mathrm{X} / \mathrm{D}=5$. 
2- Increasing the mixing chamber length ratio to $\mathrm{MC}=4.76,6.76,9.76$ and 14.76 contracts the separated flow regimes and the reattaching flow begins at an average value of axial distance ratio $\mathrm{X} / \mathrm{D}=3.25$.

3- Increasing the $\mathrm{MC}$ to a value more than 6.76 has no meaning in the mixing process as it increases the friction losses in the mixing chamber.

4- Increasing the area ratio from $\mathrm{AR}_{1}=0.057$ to $\mathrm{AR}_{2}=.0 .171$ decreases the massive recirculation zone by about 50 percent and the efficiency increased by 22 percent.

5- Reasonable agreement has been found between experimental and numerical performance.

\section{REFERENCES}

1- Dotterweith, F. H. and Moony, C.V. "How to design and operate gas jet compressors" Petroleum Refiner, Vol. 34, No. 10, Oct. 1995, pp 104-109.

2- Clanton G.W. "Design and application of the gas jet ejector on marginal gas wells" Journal of Petroleum Technology, Vol. 18, No. 4, 1966 pp.419-423

3- Da-Wen Sun "Variable geometry ejectors and their applications in ejector refrigeration systems " Energy Vol. 21, No. 10, May 1996. pp. 919-929

4- Jackson, M.L., "Aeration in Bernoulli types of devices" American Institute Chemical Engineering Journal 10, 1964, pp 836-842.

5- Davies, G.S., Mitra, A.K., Roy, A.N. "Momentum transfer studies in ejectors". Industrial and Engineering Chemistry Process Design and Development Vol. 61967, pp. 293-299.

6- Bhat, P.A., Mitra, A.K., Roy, A.N. "Momentum transfer in a horizontal liquid jet ejector". Canadian Journal of Chemical Engineering Vol. 50. 1972., pp. 313317.

7- Biswas, M.N., Mitra, A.K., Momentum transfer in horizontal multijet liquid-gas ejector. Canadian Journal of Chemical Engineering Vol. 59.1981., pp. 634-637.

8- Bhutada, S.R., Pangarkar, V.G. "Gas induction and hold-up characteristics of liquid jet loop reactors". Chemical Engineering Communication Vol.61-1987, pp. 239-261.

9- Bando, Y., Kuraishi, M., Nishimura, M., Takeshita, I., "The characteristics of a bubble column with a gas-suction-type, simultaneous gas-liquid injectionnozzle". International Chemical Engineering Vol. 30, 1990., pp. 729-737.

10- Havelka, P., Linek, V., Sinkule, J., Zahradnik, J., Fialova, M. "Effect of the ejector configuration on the gas suction rate and gas hold-up in ejector loop reactors". Chemical Engineering Science Vol. 52, 1997, pp. 1701-1713.

11-ASC, "CFX-TASCflow documentation Version 2.9.0" Advanced Scientific Computing, Ltd, Waterloo, Ontario, Canada 1999.

\section{APPENDIX 1}

\section{Notation}

$\begin{array}{ll}\text { AR } & \text { area ratio } \\ \text { Dmc } & \text { diameter of mixing chamber } \\ \text { E } & \text { Energy }\end{array}$




$\begin{array}{ll}\mathrm{P} & \text { pressure } \\ \mathrm{Pr} & \text { head ratio or (pressure ratio) } \\ \mathrm{Q} & \text { volume flow rate } \\ \mathrm{X} / \mathrm{D} & \text { mixing chamber length/ diameter of mixing chamber } \\ \mathrm{y} / \mathrm{R} & \text { radial distance to radius of mixing chamber } \\ \rho & \text { density } \\ \eta & \text { efficiency } \\ \phi & \text { mass flow ratio ( } \rho \mathrm{Q} \mathrm{s} / \rho \mathrm{Qi})\end{array}$

\section{Subscript}

$\begin{array}{ll}\mathrm{d} & \text { delivery, diffuser } \\ \mathrm{i} & \text { inlet } \\ \mathrm{in} & \text { input } \\ \mathrm{mc} . & \text { mixing chamber } \\ \mathrm{MC} & \text { mixing chamber length to diameter ratio. } \\ \text { out } & \text { output } \\ \mathrm{s} & \text { suction }\end{array}$

\section{Abbreviation}

MC Mixing chamber length to diameter ratio

CFD Computation Fluid Dynamic

\section{APPENDIX 2}

\section{A2.1 GOVERNING EQUATIONS}

\section{A2.1.1 INSTANTANEOUS EQUATIONS}

For a single species Newtonian fluid, in a Cartesian coordinate system, the conservation equations for mass, momentum and energy may be expressed in tensor form as,

$$
\begin{aligned}
& \frac{\partial \rho}{\partial t}+\frac{\partial}{\partial x_{j}}\left(\rho u_{j}\right)=0 \\
& \frac{\partial}{\partial t}\left(\rho u_{i}\right)+\frac{\partial}{\partial x_{j}}\left(\rho u_{j} u_{i}\right)=-\frac{\partial P}{\partial x_{i}}+\frac{\partial \tau_{i j}}{\partial x_{j}}+S_{u i} \\
& \frac{\partial}{\partial t}(\rho H)-\frac{\partial P}{\partial t}+\frac{\partial}{\partial x_{j}}\left(\rho u_{j} H\right)=-\frac{\partial q_{j}}{\partial x_{j}}+\frac{\partial}{\partial x_{j}}\left(u_{i} \tau_{i j}\right)+S_{E}
\end{aligned}
$$

In the above equations ${ }^{u_{i}}$ represents the velocities in the ${ }^{x_{i}}$-coordinate directions, $\mathrm{P}$ is the static pressure, $\mathrm{H}$ is the total enthalpy, $\rho$ is the density, ${ }_{i j}$ is the viscous stress tensor, ${ }^{q}$ is the molecular energy transport due to conduction, and the $\mathrm{S}$ terms are additional source terms.

The total enthalpy is defined as: 


$$
H=h+\frac{u_{i} u_{i}}{2}
$$

Where $\mathrm{h}$ is the static enthalpy of the fluid.

The molecular fluxes $\tau_{i j}$ and $q_{j}$ are expressed in terms of velocity, temperature and concentration gradients,

$$
\begin{aligned}
\tau_{i j} & =\mu\left(\frac{\partial u_{i}}{\partial x_{j}}+\frac{\partial u_{j}}{\partial x_{i}}\right)+\frac{2}{3} \mu \frac{\partial u_{i}}{\partial x_{i}} \delta_{i j} \\
q_{j} & =-\lambda \frac{\partial T}{\partial x_{j}}-\sum_{k}^{n} \Gamma_{k} h_{k} \frac{\partial Y_{k}}{\partial x_{j}}
\end{aligned}
$$

Where ${ }^{\mu}$ is the dynamic viscosity of the fluid, $\lambda$ its conductivity, and $\Gamma_{k}, h_{k}$ and $Y_{k}$ are the molecular diffusion coefficient, static enthalpy and mass fraction of species $\mathrm{k}$, respectively.

\section{A2.1.2 TIME-AVERAGING OF EQUATIONS FOR TURBULENT FLOW}

The original conservation equations are time-averaged and can be written in terms of time and Favre averaged quantities:

$$
\begin{aligned}
& \frac{\partial \bar{\rho}}{\partial t}+\frac{\partial}{\partial x_{j}}\left(\bar{\rho} \tilde{u}_{j}\right)=0 \\
& \frac{\partial}{\partial t}\left(\bar{\rho} \tilde{u}_{i}\right)+\frac{\partial}{\partial x_{j}}\left(\bar{\rho} \tilde{u}_{\mathrm{j}} \tilde{\mathrm{u}}_{\mathrm{i}}\right)=-\frac{\partial \bar{P}}{\partial x_{i}}-\frac{\partial}{\partial x_{j}}\left(\bar{\tau}_{i j}-\overline{\rho \mathrm{u}_{\mathrm{i}}^{\prime \prime} u_{j}^{\prime \prime}}+\overline{S_{u i}}\right. \\
& \frac{\partial}{\partial t}(\bar{\rho} \tilde{H})-\frac{\partial \bar{P}}{\partial t}+\frac{\partial}{\partial x_{j}}\left(\bar{\rho} \tilde{u}_{j} \tilde{H}\right)=-\frac{\partial}{\partial x_{j}}\left(\overline{q_{j}}+\overline{\rho u_{\mathrm{j}}^{\prime \prime} H^{\prime \prime}}\right)+\frac{\partial}{\partial x_{j}}\left\{\left\{\tilde{u}_{i}\left(\overline{\tau_{\mathrm{ij}}}\right)-\overline{u_{i}^{\prime \prime}} \overline{\tau_{\mathrm{ij}}^{\prime \prime}}\right\}+\overline{S_{E}}\right.
\end{aligned}
$$

The mean total enthalpy is defined as:

$\tilde{H}=\tilde{h}+\frac{\tilde{u}_{i} \tilde{u}_{i}}{2}+\tilde{k}$

Where $\tilde{k}=\frac{1}{2} \rho u_{\mathrm{i}}^{\prime \prime} u_{i}^{\prime \prime} / \bar{\rho}$, the turbulent kinetic energy.

\section{A2.1.3 TURBULENCE MODEL}

The K- $\varepsilon$ model has demonstrated a degree of robustness and generality, over many years, the final modeled form for the K-equation is

$$
\rho \frac{D}{D t}(k)=\frac{\partial}{\partial x_{j}}\left(\Gamma^{k} \frac{\partial k}{\partial x_{j}}\right)+P_{k}-\rho \varepsilon+\frac{v_{t}}{\operatorname{Pr}_{t}} \rho \beta\left(g_{j} \frac{\partial T}{\partial x_{j}}\right)
$$

where 
$\Gamma^{k}=\mu+\frac{\mu_{t}}{\sigma_{k}}$

$P_{k}=-\overline{\rho u_{i}^{\prime} u_{j}^{\prime}} \frac{\partial u_{i}}{\partial x_{j}}=$ Production of $\mathrm{k}$

$\varepsilon=\frac{\mu}{\rho\left(\frac{\partial u_{i}^{\prime}}{\partial x_{j}}\right)^{2}}=$ Dissipation of $\mathrm{k}$

$\mu=$ Dynamic viscosity of the fluid

gj is the acceleration due to gravity, $\beta$ is the isobaric compressibility and Prt is the turbulent Prandtl number.

The $\varepsilon$ equation is

$$
\rho \frac{D \varepsilon}{D t}=\frac{\partial}{\partial x_{j}}\left(\Gamma^{\varepsilon} \frac{\partial \varepsilon}{\partial x_{j}}\right)+\frac{\varepsilon}{k}\left(c_{\varepsilon 1} P_{k}-c_{\varepsilon 2} \rho \varepsilon\right)
$$

where $c_{\varepsilon 1}=1.44, c_{\varepsilon 2}=1.92$. and $\quad \Gamma^{\varepsilon}=\mu+\frac{\mu_{t}}{\sigma_{\varepsilon}}$

$\sigma_{\varepsilon}=1.3, \quad \sigma_{\mathrm{k}}=1, \quad \operatorname{Pr}_{\mathrm{t}}=0.9$

\section{A2.2 DISCRETIZATION}

CFX-TASCflow uses a finite element based finite volume method. It a finite volume method, but is based on a finite element approach of representing the geometry. Thus the method used in CFX-TASCflow retains much of the geometric flexibility of finite element methods as well as the important conservation properties of the finite volume method.

\section{A2.3 THE LINEAR SOLVER}

The multigrid solver used in CFX-TASCflow3D is an Algebraic Multigrid method (AMG) based on the Additive Correction Multigrid (ACM) strategy. This implementation of a multigrid solver has been found to be very robust. The solver employs the ACM strategy and is fully coupled (i.e., the momentum and continuity equations are solved simultaneously) and forms its blocks based on an evaluation of the relative strengths of the coefficients connecting a node to its neighbors, rather than a fixed, regular blocking. This "adaptive" approach means that the one multigrid algorithm is sufficient to reduce all the error modes in the solution, and a Block Correction scheme is not required. An unstructured-grid data structure is used by the solver, which allows all the connections resulting from grid embedding, grid attaching and periodicity to be handled fully implicitly. As well, it supports a variable-degree-offreedom per node capability that will allow other future applications to be solved with 
full multigrid. These features of the solver address all of the known weaknesses of the earlier multigrid algorithm, and thus maintain the high levels of reliability and efficiency for all the capabilities currently available.

\section{دراسة عمليه ونظرية عن تأثير طول حجرة الخلط ونسبة المساحة على أداء النافث الهوائى}

يتـاول هذا البحث نتائج التجـارب المعمليـة والحسـابية لأداء النافث الهوائى. وقد استخدمت الطريقـة الحسابية لتحليل تأثنر طول حجرة الخلط ونسبة المساحة ( نسبة مساحة النافث الى مساحة حجرة الخلط) على اداء النافث الذى تم قياسه عمليا. وقد وجد انه فى حالة استخدام حجرة خلط قصبرة (MC=1.76) ان منطقة الأنفصال فى الجزء الحلى تتم فى الطول الكلى لحجرة الخلط وتمتد الى حوالى 60 \% من

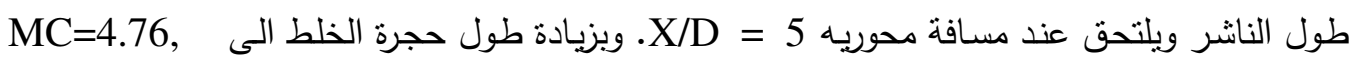
6.76, 9.76 and 14.76 فان ذلك يقلل المسحة التى يحدث فيها الأنفصال وان السريان يبدأ فى ونى الألتحاق مرة اخرى عن مسافه محوريـة X/D= 3.25 . وبزيادة طول حجرة الخلط الى قيمة أكبر من فان ذلك ليس لله معنى فى عملية الخلط حيث أنه يزيد مفاقيد الأحتكاك فى غرفة الخلط. وبزيادة نسبة المساحة من AR فى حجرة الخلط تقل بنسبة 50 \% وبنسبة زيادة لنسبة الضغط بحوالى 21\% مع زيادة للكفاءة بنسبة 22 $\%$

أخيرا تم المقارنة بين منحنى الأداء العملى والنظرى فوجد انه جيد. 